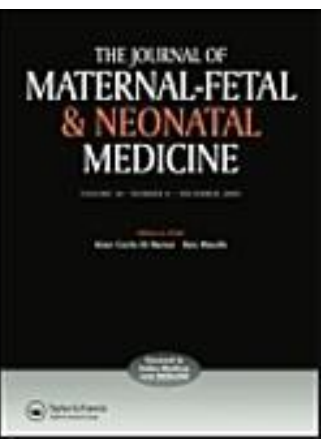

\title{
Episiotomy: an informed consent proposal
}

\begin{tabular}{|r|l|}
\hline Journal: & The Journal of Maternal-Fetal \& Neonatal Medicine \\
\hline Manuscript ID & DJMF-2019-0619 \\
\hline $\begin{array}{r}\text { Manuscript Type: } \\
\text { Aubmitted by the } \\
\text { Author: }\end{array}$ & Original Paper \\
\hline Complete List of Authors: & $\begin{array}{l}\text { Malvasi, Antonio; Santa Maria Hospital, Gynecology and Obstetric } \\
\text { Trojano, Giuseppe; Department of Obstetrics and Gynecology, } \\
\text { Ospedale Macedonio; Tinelli, Andrea; Department of Obstetrics and } \\
\text { Gynecology, Vito Fazzi Hospital, Lecce, Italy } \\
\text { Marinelli, Enrico; Sapienza University of Rome, Department } \\
\text { of Anatomical, Histological, Forensic and Orthopedic Sciences } \\
\text { Zaami, Simona; Universita degli Studi di Roma La Sapienza, Department of }\end{array}$ \\
\hline & Anatomical, Histological, Forensic and Orthopaedic Sciences \\
\hline Keywords: & episiotomy, informed consent, complications, malpractice \\
\hline
\end{tabular}

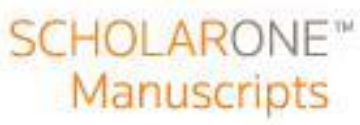




\title{
ORIGINAL ARTICLE \\ Episiotomy: an informed consent proposal
}

\section{Antonio Malvasia, Giuseppe Trojano ${ }^{b}$, Andrea Tinellic Enrico Marinelli $^{\mathrm{d}_{*}}$, Simona Zaami ${ }^{\mathrm{d} *}$}

\begin{abstract}
aDepartment of Obstetrics and Gynecology GVM Care Research Santa Maria Hospital, Bari, Italy; 'Department of Obstetrics and Gynecology 2, AOU Policlinico, Bari, Italy; 'Department of Obstetrics and Gynecology , Vito Fazzi Hospital , Lecce , Italy; ${ }^{d}$ Department of Anatomical, Histological, Forensic and Orthopedic Sciences, Sapienza University of Rome, Italy
\end{abstract}

CONTACT Simona Zaami, email: simona.zaami@uniroma1.it Department of Anatomical, Histological, Forensic and Orthopedic Sciences, Sapienza University of Rome, Italy *These authors contributed equally to this work

\begin{abstract}
Objective: Since every obstetric surgical procedure requires gaining informed consent from patient, we have set out to evaluate whether such requirement also applies to episiotomy.

Material and methods: To that end, we have conducted a thorough search of relevant scientific literature on multidisciplinary databases (Scopus, PubMed, PubMedCentral, Research Gate, Google Scholar) and articles that were published from 1989 until March 2019. The search keys used were: "episiotomy", "informed consent", "complications", "malpractice".

Results: The sources that we have ultimately drawn upon, whilst acknowledging the need for a targeted informed consent for episiotomy, do not deal with the specifics of what such consent should include, in terms of information provided and related aspects. Therefore, the Authors have laid out an episiotomy-targeted consent form, drawing upon opinions and indications from scientific societies and institutions, in order to properly reflect and document the patient's acceptance or refusal of the procedure.
\end{abstract}


Conclusions: Valid consent documentation may well prove instrumental in staving off or reducing complications, malpractice and liability, and in order to safeguard health care operators from obstetric malpractice allegations.

\section{Keywords: episiotomy, informed consent, complications, malpractice.}

\section{Introduction}

In surgical practice a principle has been reinforced that for every procedure (even entailing a minimal risk), informed consent needs to be obtained from the patient. The underestimation of the question of informed consent to episiotomy stems from the fact that it is associated with delivery itself rather than be viewed as a separate procedure. In the world a different degree of sensitivity arguably exists in the approach to episiotomy: in most Latin American countries episotomy is perceived as a possible obstetric violence [1]. On a global level, the highest rates have been recorded in the middle Eastern and Asian countries, probably on account of smaller and tighter perineum among women of Asian ethnicity [2].

Although informed consent is a crucial process in the delivery of sound obstetric care, in over $50 \%$ of cases parturients are not even asked for their consent to undergo an episiotomy. In cases where a consent form was used, the information on episiotomy that was provided to patients appeared to be non-specific and broad-ranging, encompassed within an array of obstetric procedures, thus failing to elaborate on the risks and complications inherent to the procedure. Many times, episiotomy is carried out during the last stage of delivery, sometimes under emergency conditions, therefore no time to go through an accurate informed consent phase [3,4]. Consent to undergo episiotomy should thus be obtained upon admission to the delivery room when there is still time to explain and ensure that it will be performed just in case of an emergency. However, according to the Royal College of Obstetricians and Gynecologists (RCOG), when it is necessary to gain consent from a patient during painful labor, such as to perform an episiotomy, the parturient ought to be given information between contractions, although such a scenario is arguably far from desirable [5]. Women should be encouraged to express their views on such procedures so that their carers are aware of the choices made by 
the women and act accordingly. Thorough information about episiotomy should comprise the adverse events [6]. Modern medical practice, as it is universally acknowledged, must abide by with patient consent. Even routine procedures are not above that rule. All too often, however, consent to episiotomy is not reflected in patient records, although such a procedure is in itself recognized as liable to give rise to relevant complications. In order to avoid any misunderstanding, as well as stave off litigation arising from episiotomy-related adverse outcomes, it is incumbent upon health care operators to make patients aware of of both the risks inherent to the refusal of episiotomy and those that the procedure entails. Informed consent from patients, which must be reflected in the patient's medical records, is mandatory. It is also necessary to make sure that the patient is not allergic to lidocaine without their knowing it. We therefore see fit that all patients that are potential candidates to undergo an episiotomy should be provided with all relevant information and be required to sign a consent form summing up risks and benefits associated with episiotomy, thus enabling women to make a thoroughly informed and sensible decision.

\section{Materials and methods}

A thorough search of relevant scientific literature has been carried out on multidisciplinary databases (Scopus, PubMed, PubMedCentral, Research Gate, Google Scholar) and articles that were published from 1989 until January 2019. The search keys used were: episiotomy, informed consent, complications, malpractice. Papers centered around cases and instances in which episiotomy did take place, but was not a key factor in determining a given outcome were disregarded. Furthermore, several studies have been found by sifting through the references of the selected papers, and an additional search was conducted on institutional websites for reports, guidelines, opinions and recommendations released by international and national institutions (National Institute for Health Care Excellence, Royal College of Obstetricians and Gynaecologists, American College of Obstetricians and Gynecologists,). The search was limited to English language and all articles have been independently delved into by three of the authors in order to make sure about their relevance within the framework of the present paper; only those articles deemed to be relevant by at least two of them have been ultimately selected.

\section{Results}


Our research has not brought to light any proposal for an episotomy targeted informed consent model. We have therefore sought to lay out one based on literature data and recommendations of scientific societies and health institutions. The figure 1 report a proposal form of exhaustive informed consent, which considers the recommendations of health institutions, the indications of scientific societies and the need for clarity in the doctor/midwife/patient relationship.

Fig. 1 - Proposal of informed consent targeted to episiotomy (on form bearing the visual identity of hospital or clinic

\section{INFORMED CONSENT FORM ON EPISIOTOMY}

The patient date and place of

birth.

has been provided thorough information by MD as to the advantages and risks of episiotomy during delivery.

In fact the perineal massages and other obstetrical procedures can reduce but cannot totally rule out the risk of laceration.

Therefore a selective episotomy may be carried out, after an individual assessment (on a case by case-basis) in presence of a reasonable risk of third or fourth degree tears related to:

prolonged labor ( $\geq 3 \mathrm{~h}$ with epidural or $\geq 2 \mathrm{~h}$ without epidural in nulliparous, $\geq 2 \mathrm{~h}$

with epidural or $\geq 1 \mathrm{~h}$ without epidural in multiparous, according to ACOG)

dystocia, including shoulder dystocia

the need to expedite delivery for fetal/maternal compromise

the urgency to facilitate an operative vaginal delivery or to perform an internal

maneuver

pre-existing genital mutilations

According to recommendations from the RCOG and NICE we will be performing an mediolateral episiotomy unless a specific obstetric condition requires a different episiotomy type.

The procedure will be performed with local, neuraxial or general anestehesia.

After the procedure analgesic drugs* may be administered:

*(Specify what drugs, modality of administration and dosage in order to rule out allergies).

This procedure carries the possibility of early or late adverse events such as:

puerperal genital haematoma (up to $0.4 \%$ )

dehiscence of episiotomy suture (up to $2 \%$ )

dyspareunia (up to $47 \%$ in primiparous, up to $22 \%$ in

multiparous) uncontrollable flatus passage (up to 18\%)

persistent incontinence beyond six months (extremely rare)

Date

Signature of practitioner who provided info 
Signature of midwife

Signature of anesthesiologist

Signature of the woman

\section{Discussion}

An important question is whether providing information is key to avoiding legal repercussions. In Italy, The Midwives Ethical Code spells out the duty to provide information and gain consent: Article 3, subsection 10: "The midwife, with the exception of emergency cases, shall provide patients with thorough information prior to the undertaking of any professional procedure, for the purpose of gaining informed consent based on an effective therapeutic alliance with each individual patient"

[7]. In fact, the implementation of any medical-surgical invasive practice, liable to cause damage, though formally allowed, may give rise to indemnity claims, if failing to meet the standards of best practice. In conformity with such standards, episiotomy is only warranted as an emergency procedure, which statistically occurs in a mere 5\% of vaginal deliveries [8]. The likelihood of a criminal indictment for accidental personal injury is low, but it can be pursued in cases of failure to provide thorough information and gain consent, or in case of adverse consequences occurring in the absence of indications. According to Italian tort law, if the surgical procedure has not been specified and expounded upon to the patient, consent given may be null and void, since it is based on lacking information. Compensation may be awarded if a permanent or temporary damage occurs. Not only is the damage in itself considered to be worthy of compensation, but other related aspects are as well, such as psychological distress and possible impairment (also known as "existential damage", which is tied to social and emotional repercussions such as the "inability to be or to do" as before, arising from the damage). Even in cases in which an undocumented (and not agreed upon) episiotomy was performed, resulting in no significant damage to the patient, a lawsuit may ensue anyway, on the grounds of a possible breach of the patient's right to self-determination.

It is worth underscoring that there are various other independent risk factors, such as maternal age, birth weight, and assisted vaginal delivery, that should be considered in counseling and making decisions regarding delivery modality, although episiotomy does constitute a relevant risk factor for major lacerations after vaginal delivery [9]. Furthermore, performing an intrapartum ultrasonography may be instrumental in ruling out risk factors and in order to 
prevent maternal and neonatal complications but also to shield physicians from legal liability [10]; similar diagnostic tools have advantages: improvement of fetal head's malpositions and malpresentations diagnosis; prevention of maternal and fetal childbirth complications stemming from the use of forceps or vacuum extractor; better planning of cesarean section; evidence of professional and legal soundness. Older patients set to deliver their first baby are at higher risk to suffer major tears. Whenever possible, therefore, mid-line episiotomy and assisted vaginal delivery should be forgone in such instances, particularly in cases of macrosomia [11, 12].

\section{Conclusions}

Obstetric surgical techniques call for obtaining informed consent from patients; that, however, does not universally apply to episiotomy [13].

The Authors, while pointing out that routine episiotmy should be abandoned, support the adoption of an informed consent model, which ought to be applied in cases where this procedure is taken under advisement [14].

This consent proposal includes the selective episiotomy indications, anesthesia technique to be applied, episotomy type and early and late complications possibly stemming from the procedure [15]. Valid consent documentation may well prove instrumental in staving off or reducing litigation and compensation costs, and in shiellding health care professional from obstetric violence charges [16].

\section{Disclosure statement}

The authors report no conflicts of interest.

\section{References}

[1] Zaami S, Stark M, Beck R, et al. Does episiotomy always equate violence in obstetrics? Routine and selective episiotomy in obstetric practice and legal questions.Eur Rev Med Pharmacol Sci. 2019;23:1847-1854.

[2] Zhang $M$, Wang $M$, Zhao X, et al. Risk factors for episiotomy during vaginal childbirth: A retrospective cohort study in Western China. J Evid Based Med. 2018;11:233-241.

[3] Ob-Gyns Can Prevent and Manage Obstetric Lacerations During Vaginal Delivery, Says New ACOG Practice Bulletin ACOG Continues to Recommend Against Routine Episiotomy. June 22, 2016. 
[4] Mid Essex Hospital Services NHS. Management of episiotomy. Clinical Guidelines. No. 07045, june 2016.

[5] Royal College of Obstetricians and Gynaecologists. Obtaining Valid Consent Clinical Governance Advice No. 6 January 2015.

[6] Verghese T.S., Champaneria R., Kapoor D.S., et al. Obstetric anal sphincter injuries after Episiotomy: Systematic review and metaanalysis. Int Urogynecol J 2016;27:1459-67.

[7] Codice Deontologico dell'Ostetrica/o (Italian Midwife Code of Ethics) Approved by the CNS 19th June 2010.

[8] Thorp JM, Bowes WA. Episiotomy: Can its routine use be defended? Am J Obstet Gynecol. 1989;160:1027-1030.

[9] Smith LA, Price N, Simonite V, et al. Incidence of and risk factors for perineal trauma: a prospective observational study. BMC Pregnancy Childbirth. 2013;13:59.

[10] Malvasi A, Montanari Vergallo G, Tinelli A, et al.. Can the intrapartum ultrasonography reduce the legal liability in distocic labor and delivery? J Matern Fetal Neonatal Med. 2018;31:1108-1109.

[11] Kalis V, Laine K, de Leeuw JW et al. Classification of Episiotomy: towards a standardisation of terminology BJOG 2012;119:522.

[12] Angioli R, Gómez-Marín O, Cantuaria G, et al. Severe perineal lacerations during vaginal delivery: the University of Miami experience. Am J Obstet Gynecol. 2000;182:1083-1085.

[13] Goldberg H. Informed decision making in maternity care. J Perinat Educ. 2009;18:32-40.

[14] Jiang H, Qian X, Carroli G, et al. Selective versus routine use of Episiotomy for vaginal birth. Cochrane Database Syst Rev 2017;2:CD000081.

[15] Zaami S, Montanari Vergallo G, Napoletano S, et al. The issue of delivery room infections in the Italian law. A brief comparative study with English and French jurisprudence. J Matern Fetal Neonatal Med. 2018;31:223-227.

[16] Zaami S, Stark M, Beck R, Malvasi A, Marinelli E. Does episiotomy always equate violence in obstetrics? Routine and selective episiotomy in obstetric practice and legal questions. Eur Rev Med Pharmacol Sci. 2019;23:1847-1854. 
